\title{
Review: clozapine reduces relapse and symptoms compared with typical neuroleptic drugs in schizophrenia
}

Essali MA, Rezk E, Wahlbeck K, et al. Clozapine v "typical" neuroleptic medication for schizophrenia. In: the Cochrane Database of Systematic Reviews [updated 4 March 1997]. In the Cochrane Library [database on disk and CD-ROM]. The Cochrane Collaboration; issue 2. Oxford: Update Software; 1997.

\section{Objective}

To compare the effectiveness of clozapine with typical neuroleptic drugs in patients with schizophrenia.

\section{Data sources}

Studies were identified by searching Biological Abstracts (January 1982 to May 1995), Cochrane Schizophrenia Groups' Register, EMBASE (January 1980 to May 1995), Medline (January 1966 to May 1995), PsycLIT (January 1974 to May 1995), and SCISEARCH, as well as by scanning the reference list of retrieved articles and by contacting authors of recent trials and the manufacturer of clozapine.

\section{Study selection}

Studies were selected if they were randomised controlled trials that compared the effectiveness of clozapine with typical neuroleptic drugs in patients with schizophrenia. Principal outcomes of interest were mortality, relapse, changes in mental state, behavioural changes, subjective wellbeing, family burden, suitability for discharge, working ability, and side effects.

\section{Data extraction}

Data were extracted on study duration, study design, patient characteristics, study setting, specifics of the intervention and control treatments, and the principal outcomes.

\section{Main results}

27 studies met the selection criteria, 23 of which were $<13$ weeks in duration. In the short term (up to 12 weeks), patients in the clozapine group had fewer relapses $\{p=0.037\}^{*}$ and more frequent clinically important improvements $\{\mathrm{p}<0.001\}^{*}$ than those in the typical neuroleptic drug group (table). In the short term, patients in the clozapine group also had a greater reduction in symptoms. No differences existed between the treatment groups for mortality, patient dissatisfaction, working ability, or suitability for discharge at the end of the study. In an analysis restricted to neuroleptic resistant patients, no difference was shown in relapse rates between the treatment groups $(\mathrm{n}=362,4$ studies). However, 2 of the 4 studies $(\mathrm{n}=309)$ reported a better clinical response to clozapine than to other neuroleptic drugs (odds ratio $0.14,95 \%$ CI 0.08 to 0.25 , number needed to treat 4 ), and pooling the data across all 4 studies showed a weighted mean difference between treatments in Brief Psychiatric Rating Scale total score of 9 points, which favoured clozapine.

\section{Conclusion}

Clozapine reduces relapse and symptoms and produces clinically meaningful improvement in patients with schizophrenia.

*p values calculated from data in article.

Clozapine v typical neuroleptic drugst

\begin{tabular}{|c|c|c|c|c|c|}
\hline Outcome & $\begin{array}{l}\text { Clozapine } \\
\text { weighted EER }\end{array}$ & $\begin{array}{l}\text { Neuroleptics } \\
\text { weighted CER }\end{array}$ & $\begin{array}{l}R R R \\
(95 \% C I)\end{array}$ & $\begin{array}{l}\text { Weighted } \\
\text { ARR }\end{array}$ & $\begin{array}{l}N N T \\
(C I)\end{array}$ \\
\hline Relapse & $10.8 \%$ & $13.5 \%$ & $\begin{array}{l}41 \% \\
\text { (19 to 57) }\end{array}$ & $2.7 \%$ & $\begin{array}{l}37 \\
\text { (19 to } 588)\end{array}$ \\
\hline Outcome & $\begin{array}{l}\text { Clozapine } \\
\text { weighted EER }\end{array}$ & $\begin{array}{l}\text { Neuroleptics } \\
\text { weighted CER }\end{array}$ & $\begin{array}{l}R B I \\
(C I)\end{array}$ & $\begin{array}{l}\text { Weighted } \\
\text { ABI }\end{array}$ & $\begin{array}{l}\text { NNT } \\
(C I)\end{array}$ \\
\hline $\begin{array}{l}\text { Clinical } \\
\text { improvement }\end{array}$ & $53.3 \%$ & $34.1 \%$ & $\begin{array}{l}50 \% \\
\text { (33 to 69) }\end{array}$ & $19.2 \%$ & $\begin{array}{l}6 \\
\text { (5 to } 7)\end{array}$ \\
\hline
\end{tabular}

†Abbreviations defined in glossary; RRR, RBI, ARR, ABI, NNT, and CI calculated from data in article.

Sources of funding:National Institute on Drug Abuse. USA:Al-Tal General Hospital, Syria; National Research and Development Centre for Welfare and Health, Finland; Helsinki University Central
Hospital, Finland; Medicinska Understödsforeningen Liv och Hälsa r.f., Finland; Finnish Medical Society; Cochrane Schizophrenia Group General Fund, UK.

For article reprint: Dr A Essali, Head of Department, Al-Tal General Hospital, Department of Psychiatry, 27 Al-Zahrawi Street,Al-Rawda, Damascus, Syria.Fax +1 963115117483.

Abstract and commentary also published in Evidence-Based Medicine 1977 Nov-Dec;2:182.

\section{Commentary}

Over the past 40 years, clinicians believed that all antipsychotic medications were essentially equal. In other words, these medications were thought to be equally effective with respect to the core symptoms of psychosis (ie, hallucinations, delusions, impaired communication) in spite of having variable side effects. The review by Essali et al examines the literature comparing clozapine (the prototypic "atypical" antipsychotic medication) with other classical neuroleptics. The review found that clozapine is better for the most clinically relevant outcome measures. Patients receiving clozapine had a greater reduction in symptoms, fewer motor side effects, and fewer relapses. Clozapine was particularly effective in patients who did not respond to classical neuroleptics.

The review also addresses the major drawbacks associated with clozapine, its association with neutropenia and the subsequent need for ongoing blood monitoring. The reviewers express disappointment that the trials were short (mostly <13 wk) and used a narrow range of outcome measures. They also suggest that more subjective measures and the opinions of caregivers should be included as outcome measures in future trials evaluating antipsychotic agents. Because clozapine is a relatively expen- sive drug, the inclusion of pharmacoeconomic measures in future revisions of the review would be of interest to nations and local services with limited health budgets.

The take home message from the review is that all antipsychotic medications are not equal. Consumers, caregivers, and healthcare providers can only hope that the new range of atypical antipsychotic medications inspired by clozapine will have similar superior profiles when compared with classical medications.

John McGrath, MBBS, PhD, FRANZCP Queensland Centre for Schizophrenia Research Wacol, Queensland, Australia 